\title{
NUMERICAL MODELLING OF STONE COLUMNS BENEATH A RIGID FOOTING
}

\author{
by \\ Jorge Castro \\ Group of Geotechnical Engineering \\ Department of Ground Engineering and Materials Science \\ University of Cantabria \\ Avda. de Los Castros, s/n \\ 39005 Santander, Spain \\ Tel.: +34942 201813 \\ Fax: +34 942201821 \\ e-mail: castrogj@unican.es
}

Date: January 2014

Number of words: 6,000

Number of tables: 5

Number of figures: 17 


\section{ABSTRACT}

This paper presents a set of systematic 2D and 3D finite element analyses that study the performance of groups of stone columns beneath a rigid footing. Those numerical analyses show that the number of columns and their arrangement have a small influence on the load-settlement curves. Furthermore, a reanalysis of previous laboratory data available in the literature confirms the small influence of the column configuration. That finding provides some background for homogenization techniques and validates the use of equivalent gravel trenches. This paper proposes a new simplified approach to study groups of stone columns, which involves converting all the columns of the group beneath the footing in just one central column with an equivalent area. This simplified model is used to conclude that, for settlement reduction, there is a column critical length in a homogeneous soil around twice the footing width, and high area replacement ratios beneath a rigid footing are less efficient.

KEYWORDS: Ground improvement, stone columns, numerical analyses, settlement, footings, critical length. 
$a_{r}$

$c$

$c_{u}$

$d_{c}$

$K_{0}$

$p_{a p p}$

$p^{\prime}{ }_{0}$

$S$

$S_{x}, S_{y}$

$S_{z}$

$S_{z 0}$

$x, y, z$

A

B

E

$H$

$L$

$N$

$\beta$

$\gamma^{\prime}$
Area replacement ratio: $a_{r}=A_{c} / A_{l}$

Cohesion

Undrained shear strength

Column diameter

Coefficient of lateral earth pressure at rest

Uniform applied vertical pressure

Initial mean effective stress

Centre-to-centre column spacing

Horizontal displacement

Settlement

Settlement without columns

Cartesian coordinates

Cross-sectional area

Footing width

Young's modulus

Soft soil layer thickness

Column length

Number of columns in the group

Settlement reduction factor: $\beta=s_{z} / s_{z 0}$

Effective unit weight 
Poisson's ratio

$\sigma$

Stress

$\phi$

Friction angle

$\psi$

Dilatancy angle

Subscripts:

$c, s, l \quad$ column, soil, loaded area 


\section{INTRODUCTION}

Ground improvement using stone columns, either by the vibro-replacement or vibrodisplacement methods, is a popular technique for foundation of embankments or structures on soft soils. Stone columns are vertical boreholes in the ground, filled upwards with gravel compacted by means of a vibrator. The inclusion of gravel, which has a higher strength, stiffness and permeability than the natural soft soil, improves the bearing capacity and the stability of embankments and natural slopes, reduces total and differential settlements, accelerates soil consolidation and reduces the liquefaction potential.

Stone columns are typically employed under embankments or large uniformly loaded areas. In those cases, columns are distributed in a large regular mesh and the problem is usually simplified to a "unit cell", i.e. only one column and the corresponding surrounding soil. The large number of columns justifies symmetry boundary conditions. So, the lateral boundary of the "unit cell" is rigid, frictionless and shear free. The simplicity of the model allows for analytical solutions that provide the settlement reduction [1-3].

More recently stone columns have also been deployed beneath small isolated pad or strip foundations at low or moderate loading conditions [4]. The bearing capacity of those groups of stone columns has predominantly been the focus of previous studies [58]. However, stone columns are installed in soft soils that can undergo large displacements at relatively low loads and the serviceability limit state may be critical for 
their design. Black et al. [9] identified the lack of information regarding the settlement performance and conducted small-scale laboratory tests. Similarly, Shahu and Reddy [10] performed laboratory tests and their numerical simulation. Killeen [11] studied small groups of stone columns using three-dimensional (3D) finite element analyses. They studied the influence of several geometric and material properties, such as column length, diameter, spacing and stiffness, on the load-settlement response. However, there is still little information on the influence of column arrangement and lack of clarity on the key parameters. For example, the column length to diameter ratio $\left(L / d_{c}\right)$ is frequently used but, if only $L / d_{c}$ is changed, keeping other parameters constant (e.g. the area replacement ratio and the column length), the load-settlement curve does not change noticeably, as shown in this paper.

To clarify the most important parameters and the influence of the number of columns and their position beneath a rigid footing, a set of systematic $2 \mathrm{D}$ and $3 \mathrm{D}$ finite element analyses were carried out. The paper presents the numerical models, the parametric study and their results. The load-settlement curves of different groups of stone columns show the small influence of column diameter and position. That is confirmed by a review of small-scale laboratory test data available in the literature $[6,9]$. The finite element results also offer some guidance for the design, provide some background for homogenization techniques (e.g. Schweiger [12]), validate the use of equivalent gravel trenches (e.g. Mitchell and Huber [13]), and introduce a new simplified model to study groups of stone columns, which involves converting all the columns in just one central column. This new model is used to study the influence of the area replacement ratio, $a_{r}$, and the critical column length, which may be defined as the column length beyond 
which the column does not improve further the soft soil, i.e. it does not reduce further the settlement or improve the bearing capacity [14]. To conclude, some of the findings presented in this paper are applied to a simplified design example.

\section{DIMENSIONAL ANALYSIS}

As a first approach, the variables of the problem are identified and a dimensional analysis is performed to get them in a dimensionless form. They may be classified as follows:

(a) Geometrical variables: Footing width, $B$; Soft soil layer thickness, $H$; Column length, $L$; column diameter, $d_{c}$, centre-to-centre column spacing, $s$, and number of columns beneath the footing, $N$.

(b) Initial stress state, $p^{\prime}{ }_{0}, K_{0}$, and applied vertical pressure, $p_{a p p}$.

(c) Soil and column properties: stiffness and strength.

(d) Results, e.g. settlement, $s_{z}$.

As the paper focuses on the column arrangement, the geometrical variables are analysed in detail and just a general overview of the others is presented. So, a full dimensional analysis using the Buckingham's theorem is not presented here. The soil properties depend on the constitutive model but they are either dimensionless or have units of pressure. The latter ones are typically normalised using the initial stress state (e.g. $c_{u}\left(p^{\prime}{ }^{\prime}\right)$. The applied vertical pressure may be normalised using either the initial stress state or a soil property (e.g. $\left.p_{a p p} / c_{u}\right)$. The column properties that have units are usually normalised by the soil corresponding ones (e.g. the stiffness modular ratio $E_{c} / E_{s}$ ). 
Moving on to the results, the settlement is commonly related to the settlement without columns, i.e. the settlement reduction factor, $\beta=s_{z} / s_{z 0}$, to highlight the achieved improvement with the stone column treatment.

A geometrical dimensionless parameter that is crucial and widely used is the area replacement ratio, $a_{r}$, which provides the percentage of soft soil replaced by gravel. Assuming that all the columns are under the footing because it is generally more efficient [8], $a_{r}$ is defined as the area of the columns, $A_{c}$, divided by the loaded area, $A l$, which is equal to $B^{2}$ for a square footing. Another parameter that is sometimes used in the literature is the column length to diameter ratio, $L / d_{c}$. However, it will be shown in this paper that its influence on the load-settlement response is small and it is more appropriate to use the ratio $L / B$ instead of $L / d_{c}$, because the deformation mechanism is mainly driven by the footing not by the individual columns, as Wood et al. [6] already justified by physical observations. $B$ and $d_{c}$ are interrelated through $a_{r}$ and $N$. The relative position of the columns (gravel) beneath the footing, i.e. if they are close to the centre or the edge of the footing, does not have a significant influence on the loadsettlement curve but its influence is still slightly higher than that of the number of columns, $N$, as it is demonstrated in this paper. Lastly, the layer thickness, $H$, is indirectly included in the settlement without columns, $s_{z 0}$. However, for a small group of columns, $H / B$ is high, and therefore, $H$ is not a crucial variable of the problem because $S_{z 0}$ depends mainly on the footing width, $B$. On the contrary, for a large group of columns, $H / B$ is low, and $B$ is not decisive (e.g. the width of an embankment). In the latter case, the column length is normalised by $H$ instead of $B$, to distinguish between end-bearing and floating columns. 
So, only five of the geometrical variables are independent. Here, the following are used: $H / B, L / B, a_{r}, N$ and the column position.

\section{NUMERICAL MODELS}

Numerical simulations were performed to provide a better understanding of the influence of the column arrangement beneath rigid footings on the load-settlement response. The study started with a simple reference case and parametric studies were performed. The theoretical framework of the numerical simulations is first provided.

\subsection{Basic assumptions and theoretical background}

The finite element method (e.g. $[15,16])$ was used for the numerical simulations. The codes Plaxis 3D 2012 [17] and Plaxis 2D 2011 [18] were used for the full 3D models and the simplified 2D axisymmetric models, respectively. These codes automatically generate the finite element mesh using a triangulation procedure, but global and local mesh refinements may be defined to ensure a good quality of the mesh. When dealing with plastic materials, i.e. non-linear problems, an implicit integration scheme and an automatic step size procedure [19] are used. The Modified Newton-Raphson method is also used to avoid updating the global stiffness matrix. Convergence is achieved when both a local and a global error criterion are fulfilled. The global error criterion is the percentage of unbalanced forces; $1 \%$ is used here. The local error criterion limits the number of inaccurate Gauss points [17]. 
The soft soil and the stone columns were modelled as continuum elements using 10node tetrahedral elements for the 3D cases and 15-node triangular elements for $2 \mathrm{D}$. Perfect bonding between soil and columns at their interface was modelled, as it is common practice (e.g. Ambily and Gandhi [20]) because stone columns are tightly interlocked with the surrounding soil. The rigid footing was assumed as perfectly rough and modelled as a very stiff plate that produces uniform settlements. The finite elements for the footing were 6-node triangular elements in 3D and 5-node line elements in 2D. Those elements have translational and rotational degrees of freedom and their properties are the flexural rigidity and the normal stiffness.

All the numerical simulations were performed using a small strain formulation and a staged construction process was modelled. Initially, the natural soft soil was modelled with a horizontal ground surface and a constant thickness. Geostatic initial stresses were generated using the soil unit weight and the coefficient of lateral earth pressure at rest, $K_{0}$. Later, the footing and the column or columns were "wished-in-place", ignoring the changes in the natural soil due to column construction [21]. Finally, the loading on the footing was simulated. Drained conditions were assumed for all the process, i.e. no excess pore pressures were generated. Consequently, the soil and column response was studied in effective stresses.

\subsection{Reference case}

The reference case consists of only one stone column under the centre of a square rigid footing. The footing width, $B$, is $5 \mathrm{~m}$ and the column diameter $\left(d_{c}=1.78 \mathrm{~m}\right)$ was chosen 
to give an area replacement ratio of $a_{r}=10 \%$. The column is considered to reach a rigid substratum at $10 \mathrm{~m}$ depth. So, the column is end-bearing $(L / H=1)$ and has a length of $L=10 \mathrm{~m}$. To take advantage of the symmetry of the problem, only a quarter is modelled (Figure 1). The symmetry would allow for further reduction, but that is not useful in this particular numerical code. Parametric studies were performed to study the model dimensions and a ratio of model to footing breadth of 6 was considered enough. The bottom boundary is fixed and roller vertical conditions are assumed for the lateral boundaries.

It is worth noting that this reference case is not equivalent to the isolated stone column that is considered in many studies (e.g. Hughes and Withers [14]) because in those cases the load is only applied on top of the column, which means an $a_{r}=100 \%$ and, as discussed later, it is generally less efficient at reducing the settlement.

The soil profile was simplified to only one homogeneous soil layer. As a first approach, the soil and the column were assumed as linear elastic materials with a Poisson's ratio of $v=0.33$ and Young's moduli of $E_{s}=2 \mathrm{MPa}$ and $E_{c}=30 \mathrm{MPa}$, respectively. That means a modular ratio of 15 . Common soil and column properties $[4,5,22]$ were used for the idealised case analysed in this paper. Assuming an elastic behaviour for the column saves computation time but it is not realistic. Therefore, in a next step, an elasticperfectly plastic behaviour was considered for the column using the Mohr-Coulomb yield criterion and a non-associated flow rule, with a constant dilatancy angle. Although the crushed stone (gravel) used for the column backfill is a pure frictional material, a small cohesion $\left(c_{c}=0.1 \mathrm{kPa}\right)$ was used to avoid numerical problems. The reported values 
of the friction and dilatancy angles of the column backfill are usually just reasonable estimations of the "in-situ" properties, because it is very difficult to measure them in the field [23]. Typical values of $\phi_{c}=45^{\circ}$ and $\psi_{c}=15^{\circ}$ were chosen. Those are usually peak values because the column material is compacted by the vibrator and is in a dense state [23]. Those values are assumed as material constants because a perfectly plastic model is used here. Under small footings, considerable plastic strains may also appear in the surrounding soil. Hence, the Mohr-Coulomb yield criterion was also applied to the soft soil in a third case $\left(c_{s}=3 \mathrm{kPa}\right.$ and $\left.\phi_{s}=23^{\circ}\right)$. The soil is considered as a non-dilatant material. In the following, those three cases are referred to as elastic (both soil and column behave as elastic materials), elasto-plastic (plastic strains are considered in the column) and plastic (plastic strains may appear in the soil and the column).

A uniform vertical pressure of $p_{a p p}=100 \mathrm{kPa}$ was applied on the rigid footing. This applied pressure is high enough to produce significant plastic strains. The ground water level is at the surface but pore water pressures were not modelled and an effective unit weight of $\gamma^{\prime}=10 \mathrm{kN} / \mathrm{m}^{3}$ for soil and column was directly considered. The coefficient of lateral earth pressure at rest was set equal to $K_{0}=0.6$, using the Jaky's formula for the soil and disregarding installation effects [21].

\subsection{Parametric studies}

Using the reference case as a starting point, parametric studies were carried out varying several properties:

(a) Column arrangement. The number of columns, $N$, the centre-to-centre column 
spacing, $s$, and its position was varied. Typical column configurations were used. For the sake of comparison, the number of columns was varied without changing the area replacement ratio, $a_{r}$, and consequently, the diameter of the columns is obtained using $a_{r}, N$ and $B$.

(b) Other geometric factors. The size of the footing $B$, the length of the columns $L$ (floating columns), the soft soil layer thickness $H$ and the area replacement ratio, $a_{r}$.

(c) Material properties. For the elastic case, the modular ratio was varied in the common range $E_{c} / E_{s}=15,30,45$ and 60 . In another parametric study, several strengths of the column were tried for the elastic-plastic case; and for the plastic case, just the strength of the soil was altered.

\subsection{Mesh sensitivity analyses}

Some mesh dependency was foreseen due to the problem configuration, i.e. a rigid footing in a 3D mesh. A preliminary analysis of several column groups confirmed the mesh dependency, especially in the plastic case. Due to computational restrictions, the number of elements is limited in the $3 \mathrm{D}$ mesh. Therefore, for the mesh sensitivity analyses, the square footing was changed to a circular one with the same area to have axial-symmetry and model the problem also in a fine enough 2D mesh (Figure 2) [18]. In fact, the main improvement in the $2 \mathrm{D}$ simulations is not caused by the number of elements but by their higher order (15-node triangular elements in 2D and 10-node tetrahedral elements in 3D). 
The results of the mesh sensitivity analyses are summarized in Figure 3, where the settlement simulated using the $3 \mathrm{D}$ mesh is compared with that using the fine enough $2 \mathrm{D}$ mesh. For each number of elements, the most accurate mesh was also searched, i.e. refining the mesh in the area of interest (footing and column) and using a coarse mesh in the far field (Figure 1). For all the parametric studies, it was decided to use comparable meshes of around 60-70 thousand elements with the same degree of relative refinement. Although those meshes slightly underpredict the settlement (around 5\% in the plastic case), they are valid to compare and identify trends in the parametric studies.

\section{RESULTS AND DISCUSSION}

\subsection{Column position}

The first parametric study focuses on the influence of column spacing, or more precisely, the relative position of the columns beneath the footing. A group of four stone columns $(N=4)$ is used, keeping constant the area replacement ratio of the reference case $\left(a_{r}=10 \%\right)$; so, $d_{c}=0.89 \mathrm{~m}$. The spacing between columns is varied from $s=1$ to $4 \mathrm{~m}$

(Figure 4). The settlements of the groups of columns are compared with the settlement of the reference case ( 1 column) and similar results are found (Figure 5). On one hand, the settlement is slightly lower when the columns are close to the edges of the footing for the elastic case and on the other hand, the settlement is higher for the plastic case. The two main effects that control the influence of the column position on the settlement reduction are:

- when the columns are close to the edges, they tend to support higher vertical stresses because the stresses are higher at the edges for a rigid footing (Figure 
$6)$

- when the columns are close to the centre, the surrounding vertical and horizontal stresses are higher and, therefore, the columns have a better lateral confinement.

Both effects mostly compensate each other, but depending on the soil and column properties one may be slightly better than the other (Figure 5). For the elastic case, if the columns are close to the edges $(s=4 \mathrm{~m})$, they support higher vertical stresses than those close to the centre $(s=1 \mathrm{~m})$ (Figure 6$)$. When plastic strains appear in the column, the beneficial effect of positioning the columns close to the edges is reduced. Moreover, for the plastic case, if the columns are close to the edges, their lateral confinement is reduced because plastic strains develop in the surrounding soil. So, the horizontal displacements are higher at shallow depths (Figure 7) and the lateral expansion of the columns, i.e. the difference between the maximum and the minimum horizontal displacements at the column borders, is clearly larger for the columns placed near the footing edges $(s=4 \mathrm{~m})$.

The column position influences the mode of deformation. So, bulging is the main mode of deformation for centre columns, while shearing is more evident in columns at the footing edges (Figure 8). The zones of maximum shearing and bulging within the columns are directly related to the deformation beneath a rigid footing.

\subsection{Number of columns}

The next parametric study focused on the influence of the number of columns, which 
was varied between $N=1$ and 24 in multiples of 4 to retain the symmetry. The variation of the number of columns inevitably leads to some changes in the column position. To reduce that influence, all the columns were uniformly placed along a square with a side length of $4 \mathrm{~m}$. Besides, two different column configurations were used, one with a column at the corner of the square and another with columns just on the sides (Figure 9).

The results show the small influence of the number of columns on the settlement reduction (Table 1). There are some differences but they may be attributed mainly to the differences in the column position because they follow the same trends as those in the previous section. It is worth noting that for each number of columns, the ratio $L / d_{c}$ is different (from roughly 5 up to 27 ) because $a_{r}=10 \%$ is kept constant. That demonstrates the minor influence of the $L / d_{c}$ ratio on the settlement reduction. Just for very high values, i.e. very slender columns, there may appear second order effects or low-quality finite elements.

Sometimes in the literature, an increasing number of columns under the footing is considered to have a beneficial effect because the columns are better laterally confined (e.g. Priebe [24]). That is when an increasing number of columns means a larger footing, as it happens in reality because the column diameter is usually fixed by the equipment and soil conditions. However, for the sake of clarity and correctness, the column confinement is controlled by the $H / B$ ratio. 


\subsection{Soil and column properties}

As already mentioned, for the elastic case, the modular ratio was varied in the common range $E_{c} / E_{S}=15,30,45$ and 60 . In another parametric study, several strengths of the column were tried for the elastic-plastic case, varying the friction and dilatancy angles at the same time (see Table 2). For the plastic case, just the strength of the soil was altered.

Small differences were found between different column configurations (Table 2). The material properties slightly affect the two commented effects related to the column position. So, for example, higher soil strengths improve the lateral confinement of the columns and reduce a little the beneficial effect of positioning the columns near the centre. In the following, only the plastic case is used because it is the most interesting.

\subsection{Soil layer thickness and footing width}

The soil layer thickness was varied to study its influence on the settlement reduction (Table 3). For end-bearing columns $(L=H)$, that is analogous to vary the footing width because the ratio $H / B$ is the governing parameter. In fact, $H / B$ indicates the extension of the load and whether it is a small footing or a large loaded area that can be studied using the "unit cell" concept. When $H / B$ decreases, the columns are better laterally confined, if they are not near the footing edges. So, the positive effect of positioning the columns in the centre of the footing for the plastic case is enhanced when $H / B$ decreases, especially below 1 . 


\subsection{Column length}

So far, only end-bearing columns had been modelled. Now, the column length was reduced to study its influence (Figure 10). For floating columns, the column position is slightly more relevant than for end-bearing columns because there is a new effect:

- Column punching or penetration into the underlying soil, which is related to the deformation of the soil layer that is not improved beneath the columns.

For the same area replacement ratio, column penetration into the underlying soil is greater when there is less number of columns, and with closer spacings. Wood et al. [6] already showed that column penetration is greatest when the columns are in the middle of the footing, they are short and the area replacement ratio is high. It is necessary to understand that beneath a rough rigid square footing, a pyramid of soil is pushed down with the footing and shear strains concentrate along the sides of the pyramid (Figure 11). Its base corresponds to the footing but the depth changes during the loading process. Initially, it is related to the pressure bulb and at failure, it depends on the mobilized strength of the soil beneath. So, if the soil is improved with stone columns, a deeper area is affected because the average strength and stiffness beneath the footing increases. Consequently, the depth of the zone of influence increases with the $a_{r}[6]$. The depth of this pyramid determines the critical length of the columns, i.e. the length of the columns beyond which the improvement is negligible, either for the bearing pressure or the settlement reduction. A critical length for the settlement reduction of $L / B=1.5$, as proposed by Wehr [8], seems an acceptable approximation for this case (Figure 12). The critical length for the bearing pressure is shorter than that for the settlement reduction. So, if no distinction is made, it usually refers to the longer one, 
corresponding to the settlement reduction. In stratified soils, the critical lengths change and may be not so clear [11].

When the column tip is near the vertex of the pyramid created by the maximum shear strain contours, the column notably punches into the underlying soil, e.g. for a central column and $L / B$ around 1 (Figure $8 \mathrm{c}$ ). Therefore, columns near the edges give slightly less settlement than central columns for those column lengths (Figure 10).

The number of columns has less influence on the settlement reduction than their position (Table 4). Nevertheless, an increasing number of columns reduces the column punching because it distributes the load on the underlying layer; therefore, slightly less settlement is computed. When there are many columns, they are short and closelyspaced, a block deformation pattern is observed [11].

In conclusion, when floating columns reach the critical length, their behaviour is similar to end-bearing columns. If they are shorter, distributing the columns beneath the footing (more columns and near the edges) gives slightly less settlement. However, the differences are still small (Figure 10 and Table 4).

For the sake of simplicity, the settlements for an applied pressure of $p_{a p p}=100 \mathrm{kPa}$ are compared throughout the paper, but the results and conclusions are also valid for the entire load-settlement curves (Figure 13); only, when approaching the bearing pressure, the trends in the most beneficial configuration may change. Very high settlements are 
necessary to reach failure. As an additional check, the factor of safety for an applied pressure of $p_{a p p}=100 \mathrm{kPa}$ was obtained using the " $c-\phi$ reduction" process [17]. This technique gradually reduces the strength of the materials ( $c$ and $\tan \phi$ ) by a factor and when failure occurs, that reduction factor can be considered the factor of safety. Very similar values of the reduction factor around 1.47 were obtained for different column arrangements. The differences with the classical definition of the factor of safety for footings (in terms of the applied load instead of the soil strength) are evident in this case (the bearing pressure is around 3 times the applied pressure).

\subsection{Area replacement ratio}

The value of $a_{r}=10 \%$ may be low for a small footing because it has been chosen to have a broad range of variation of column spacing and number of columns. However, similar results are obtained for higher values of $a_{r}$ (Table 5). There are only subtle differences for floating columns because the punching of the columns increases with the area replacement ratio [6]. Obviously, for $a_{r}=100 \%$, i.e. only one column beneath the footing footprint, there is just a unique column arrangement.

\section{ANALYSIS OF PREVIOUS RESEARCH DATA}

This section analyses previous research data available in the literature. A reanalysis of a set of high-quality laboratory experiments performed by Black et al. [9] shows the small differences caused by the number of columns beneath the footing and by the $L / d_{c}$ ratio (Figure 14). The settlement performance of a small group of 3 columns was very similar 
to that of an isolated column for the same values of $a_{r}, L / H$ and $L / B$. The small differences between $L / H=0.62$ and 1 are also visible, which means that the column length ( $L / B=4.1$ and 6.7 , respectively) is higher than critical.

Wood et al. [6] performed small-scale tests of groups of stone columns in kaolin clay. The load-settlement response of groups that have different column radius and spacing but the same area replacement ratio is very similar (Figure 15). Only one case gives slightly higher bearing pressure (Figure 15a) because it has $25 \%$ more columns outside the footing footprint. So, these laboratory results also agree with the presented numerical study.

Killeen [11] briefly studied the influence of the column position relative to the edge of the footing on the load-settlement response. He modelled numerically a group of four columns under a square rigid footing $(B=3 \mathrm{~m})$ at 3 different spacings $(s=1,1.5$ and $2 \mathrm{~m})$ for the whole range of column lengths and found very small differences. Slightly less settlement was computed when the columns were close to the edges of the footing. This paper attributes that subtle trend to a good lateral confinement of the columns provided by the surrounding soil (with an upper rigid crust). Consequently, the surrounding soil does not reach failure, i.e. its passive state. The soil profile was based on that of the well-documented Bothkennar test site and the Hardening Soil model [25] was used to reproduce the behaviour of the soil and the columns. The Hardening Soil model uses the Mohr-Coulomb failure criterion and is able to reproduce both shear and compression hardening using hyperbolic laws and the classical theory of plasticity. 


\section{DESIGN APPLICATIONS}

This paper shows the small influence of the column arrangement in groups of stone columns beneath a rigid footing on the improvement achieved with the columns. The presented numerical results and the review of published research data demonstrate that groups of stone columns with the same area replacement ratio, but with different number and location of the columns, lead to similar load-settlement curves. That similarity provides some theoretical background for several widely-used simplified modelling techniques that do not account for the number of columns and their location, such as homogenization (e.g. [12]) or the use of equivalent gravel trenches (e.g. [13]). In this paper, very similar results were found for the full $3 \mathrm{D}$ model and for the $2 \mathrm{D}$ axisymmetric model with an equivalent cylindrical trench (Table 4), which proves the validity of this simplified modelling technique. The full validation of the homogenization technique is beyond the scope of this paper because it requires the use of specific constitutive models (e.g. [12]) or a proper matching of the equivalent material properties.

Here, for the sake of simplicity, it is proposed to transform the whole group of columns to just one central column with the same cross-sectional area, and study the problem in axial-symmetry. That "one column" model is useful not only for numerical analyses but also for analytical approaches. For floating columns that do not reach the critical length, equivalent cylindrical trenches (e.g. [13]) may be used to account for the column position and be slightly more accurate (Table 4). 
The simplified model of only one column is used here to investigate further the influence of the area replacement ratio and the critical column length. Low ar notably reduce the settlement but $a_{r}$ greater than $100 \%$ reduce the settlement very little, especially for column lengths higher than critical (Figure 16a). That trend is not so evident for the bearing pressure because the improvement is more linearly proportional to the $a_{r}$ (Figure 16b), which is related to the zones of maximum shear strains (Figure 11b). That is why there is controversy about the use of columns outside the loaded area, because they help to increase the bearing capacity but they do not reduce the settlement notably. To easily reach failure numerically, the safety factor for an applied pressure of $p_{a p p}=100 \mathrm{kPa}$ was obtained using the " $c-\phi$ reduction" process [18]. The failure mechanism may be slightly shallower using this technique because the friction angle is lower than the real one, but in this case the differences are not important.

For failure conditions, an increase in the area replacement ratio means a roughly linear increase in the average shear strength (through the friction angle). That explains the linearity of the curve in Figure 16b. As the failure mechanism extends beyond the footing footprint (Figure 11b), columns in that zone still improve the bearing pressure. On the other hand, for serviceability, the settlement reduction factor, $\beta$, decreases roughly exponentially with the area replacement ratio because the column improvement means not only an increase in the average stiffness but also an important reduction of the plastic strains. The higher shear strength of the columns and their dilatant behaviour reduce the compressive plastic strains. Under working loads, the pressure bulb deploys mainly beneath the footing (Figure 11a) and, therefore, columns outside the footing faintly reduce the settlement. 
A detailed analysis of the critical length of the column confirms that it is around $1.5-2 B$ for settlement reduction (Figure 17). When the soil layer thickness is close to the critical column length, the critical length is slightly reduced. The critical length depends, in theory, on the $a_{r}$ [6], but the differences are small. For the bearing pressure, the critical length is lower, around $0.5 \mathrm{~B}$, because it is related to the failure mechanism (Figure 11b).

In practise, uniformly distributed columns beneath the footing is the usual configuration. The small influence of the column arrangement on the load-settlement curve found in this paper justifies that construction practise, because uniformly distributed columns are more beneficial for some other factors not included in this study, such as bending moments in the footing, soil drainage and easiness of construction.

\section{DESIGN EXAMPLE}

A simplified example has been selected to show the application of some of the findings presented in this paper. The case is a rigid square footing under a vertical pressure of $100 \mathrm{kPa}$ on a quite uniform soft clay layer $10 \mathrm{~m}$ thick, which is underlain by bedrock. The footing width, $B$, is $5 \mathrm{~m}$. The square footing is transformed to a circular footing with the same area $(D=5.64 \mathrm{~m})$. The column and clay properties are those of the plastic case used in this paper. The final (drained) settlement of that footing is around $30 \mathrm{~cm}$ and the consolidation time is high. As that is not admissible, a stone column improvement is proposed to reduce both the final settlement and the consolidation time. 
The column design should meet the requirement of an allowable settlement of $15 \mathrm{~cm}$.

Firstly, the column length is chosen as roughly twice the footing width and, evidently, not higher than the soft layer thickness $(L \approx 2 B \leq H)$. In this case, the column length is $L=10 \mathrm{~m}$. Next, an area replacement ratio is calculated to achieve the allowable settlement. A 3D model of the footing and the columns would take a lot of time, but that may be done using the proposed "one column" approach. So, an axisymmetric finite element model (similar to the model shown in Figure 2) is enough to get the diameter of the equivalent column, $2.5 \mathrm{~m}$ in this case. That means an area replacement ratio of $a_{r}=20 \%$.

Once the area replacement ratio is obtained, the number of columns depends on their diameter, $a_{r}=N \cdot\left(\pi / 4 \cdot d_{c}^{2}\right) / B^{2}$. The column diameter is not usually a design variable and is fixed by the construction equipment (diameter of the poker), construction technique (dry or wet method) and the soil properties [5]. Assuming that for this case, the construction equipment and construction site conditions are such that the diameter of the columns is roughly $1 \mathrm{~m}, 7$ columns are necessary to achieve the calculated area replacement ratio $\left(a_{r}=20 \%\right)$. As a uniform distribution of the columns is the most convenient configuration if practical issues are considered, those 7 columns may be uniformly distributed beneath the footing in a hexagon with a central column. 


\section{CONCLUSIONS}

The presented numerical analyses and the review of laboratory test data available in the literature show the small influence of the column arrangement in groups of stone

columns beneath a rigid footing on the load-settlement response. Only subtle differences were found.

For column lengths higher than critical, if the surrounding soil provides enough lateral support, positioning the columns near the edges is slightly better to reduce the settlement. In those cases, shearing is the main deformation mode. On the contrary, if the surrounding soil does not provide a good lateral support, columns in the middle give slightly less settlement and they mostly bulge.

For columns shorter than critical, column arrangement is a bit more relevant because punching into the underlying soil gets important. Distributing the columns beneath the footing (more columns and near the edges) reduces column penetration into the underlying soil and, therefore, slightly less settlement is computed.

The small influence of the column arrangement on the load-settlement response provides some theoretical background for existing simplified modelling techniques, such as homogenization or the use of equivalent gravel trenches for groups of stone columns. Another simplified model, namely the use of only one equivalent central column, is here proposed. 
The following general recommendations for a group of small columns beneath a rigid footing and in a homogeneous soil layer may be derived:

- Uniformly distributed columns are slightly more beneficial.

- The column length to diameter ratio $\left(L / d_{c}\right)$ is not relevant.

- Column length around critical $(\approx 2 B)$ is more efficient.

- $a_{r}$ should not approach $100 \%$ for settlement reduction, as it is less efficient. If possible and necessary, $B$ may be increased. 


\section{ACKNOWLEDGEMENTS}

The work presented is part of a research project on "An integrated calculation procedure for stone columns, considering the influence of the method of installation", for the Spanish Ministry of Science and Innovation (Ref.: BIA2009-13602).

\section{REFERENCES}

[1] Balaam NP, Booker JR. Effect of stone column yield on settlement of rigid foundations in stabilized clay. Int J Num Anal Meth Geomech 1985; 9(4): 331351.

[2] Castro J, Sagaseta C. Consolidation around stone columns. Influence of column deformation. Int J Numer Anal Meth Geomech 2009; 33(7): 851-877.

[3] Pulko B, Majes B, Logar J. Geosynthetic-encased stone columns: Analytical calculation model. Geotextiles Geomembranes 2011; 29(1): 29-39.

[4] Watts KS, Johnson D, Wood LA, Saadi A. An instrumented trial of vibro ground treatment supporting strip foundations in a variable fill. Géotechnique 2000; 50(6): 699-708.

[5] Barksdale RT, Bachus RC. Design and construction of stone columns. Report FHWA/RD-83/026. Springfield: Nat Tech Information Service; 1983.

[6] Wood DM, Hu W, Nash DFT. Group effects in stone column foundations: model tests. Géotechnique 2000; 50(6): 689-698. 
[7] McKelvey D, Sivakumar V, Bell A, Graham J. Modelling vibrated stone columns in soft clay. Proc ICE - Geotech Eng 2004; 157(3): 137-149.

[8] Wehr J. Stone columns - single columns and group behaviour. Proc 5 Int Conf Ground Improvement Tech, Kuala Lumpur; 2004, p. 329-340.

[9] Black JA, Sivakumar V, Bell A. The settlement performance of stone column foundations. Géotechnique 2011; 61(11): 909-922.

[10] Shahu J, Reddy Y. Clayey Soil Reinforced with Stone Column Group: Model Tests and Analyses. J Geotech Geoenviron Eng 2011; 137(12): 1265-1274.

[11] Killeen M. Numerical modelling of small groups of stone columns. PhD Thesis. National University of Ireland, Galway; 2012.

[12] Schweiger HF. Finite element analysis of stone column reinforced foundations. PhD Thesis, University of Wales, Swansea; 1989.

[13] Mitchell JK, Huber TR. Performance of a stone column foundation. J Geotech Eng 1985; 11(2): 205-223.

[14] Hughes JMO, Withers NJ. Reinforcing of soft cohesive soils with stone columns. Ground Eng 1974; 7(3): 42-49.

[15] Zienkiewicz OC. The Finite Element Method - $3^{\text {rd }}$ Edition. McGraw-Hill, London; 1977.

[16] Potts DM, Zdravkovic L. Finite element analysis in geotechnical engineering: theory. Thomas Telford, London; 1999.

[17] Brinkgreve RBJ, Engin E, Swolfs WM. Plaxis 3D 2012 Manual. Plaxis bv, the Netherlands; 2012. 
[18] Brinkgreve RBJ, Swolfs WM, Engin E. Plaxis 2D 2011 Manual. Plaxis bv, the Netherlands; 2011.

[19] Van Langen H, Vermeer PA. Automatic step size correction for non-associated plasticity problems. Int J Num Meth Eng. 1990; 29: 579-598.

[20] Ambily AP, Gandhi SR. Behavior of stone columns based on experimental and FEM analysis. J Geotech Geoenviron Eng. 2007; 133(4): 405-415.

[21] Castro J, Karstunen M. Numerical simulations of stone column installation. Can Geotech J 2010; 47(10): 1127-1138.

[22] Kirsch F. Experimentelle und numerische Untersuchungen zum Tragverhalten von Rüttelstopfsäulengruppen. PhD Thesis, TU Braunschweig; 2004.

[23] Herle I, Wehr J, Arnold M. 2009. Soil improvement with vibrated stone columns - influence of pressure level and relative density on friction angle. In Karstunen \& Leoni (eds.), Geotechnics of Soft Soils - Focus on Ground Improvement. Taylor \& Francis Group, London; 2009, p. 235-240.

[24] Priebe HJ. Design of vibro replacement. Ground Eng 1995; 28(10): 31-37.

[25] Schanz T, Vermeer PA, Bonnier PG. The hardening-soil model: Formulation and verification. In Brinkgreve (ed.), Beyond 2000 in Computational Geotechnics. Balkema, Rotterdam; 1999, p. 281-290. 


\section{TABLE CAPTIONS}

Table 1. Settlement ( $\mathrm{mm}$ ) for different number of columns.

Table 2. Settlement $(\mathrm{mm})$ for different material properties: (a) Modular ratio; (b) Column strength; (c) Soil strength.

Table 3. Settlement ( $\mathrm{mm}$ ) for different soil layer thicknesses.

Table 4. Settlement (mm) for different column lengths.

Table 5. Settlement (mm) for different area replacement ratios. 


\section{FIGURE CAPTIONS}

Figure 1. 3D finite element model. Reference case.

Figure 2. 2D finite element model. Reference case. Circular footing.

Figure 3. Mesh sensitivity analyses.

Figure 4. Groups of stone columns for different spacings.

Figure 5. Influence of column position.

Figure 6. Vertical stresses beneath the footing. Diagonal section. (a) No columns; (b) $N=4$.

Figure 7. Horizontal displacements at $1 \mathrm{~m}$ depth. Diagonal section.

Figure 8. Deformation modes: (a) Bulging; (b) Shearing; (c) Punching. Deformed mesh (amplified 10 times). Cross section.

Figure 9. Groups of stone columns for different number of columns.

Figure 10. Influence of column length for different column positions.

Figure 11. Incremental shear strains beneath the rough rigid footing. No columns. Cross section. (a) $p_{a p p}=100 \mathrm{kPa}$; (b) $p_{a p p} \approx 180 \mathrm{kPa}$, at failure.

Figure 12. Settlement reduction for different column lengths.

Figure 13. Load-settlement curves.

Figure 14. Comparison between small-group and isolated column. Laboratory tests (Data taken from Black et al. [9]).

Figure 15. Comparison between different number of columns. Laboratory tests (Data taken from Wood et al. [6]).

Figure 16. Effectiveness of area replacement ratio in group of columns. (a) Settlement reduction; (b) Bearing pressure.

Figure 17. Critical column length for different area replacement ratios. 
Table 1. Settlement $(\mathrm{mm})$ for different number of columns.

\begin{tabular}{lrcccccc}
\hline & \multicolumn{4}{c}{ Elastic } & \multicolumn{2}{c}{ Elasto-plastic } & \multicolumn{2}{c}{ Plastic } \\
& $L / d_{c}$ & Corner & Sides & Corner & Sides & Corner & Sides \\
\hline 2D & 5.6 & \multicolumn{2}{c}{100.9} & \multicolumn{1}{c}{123.4} & 206.6 \\
Circular & 5.6 & \multicolumn{2}{c}{100.8} & \multicolumn{2}{c}{123.0} & \multicolumn{2}{c}{198.5} \\
$N=1$ & 5.6 & \multicolumn{2}{c}{99.1} & \multicolumn{2}{c}{119.8} & \multicolumn{2}{c}{199.1} \\
$N=4$ & 11.2 & 93.4 & 96.5 & 118.2 & 119.1 & 204.4 & 198.7 \\
$N=8$ & 15.9 & 94.7 & 95.9 & 118.5 & 119.0 & 203.0 & 198.4 \\
$N=12$ & 19.4 & 94.8 & 96.0 & 118.5 & 119.1 & 200.1 & 198.3 \\
$N=16$ & 22.4 & 95.2 & 95.9 & 118.8 & 119.1 & 199.5 & 198.1 \\
$N=20$ & 25.1 & 95.4 & 96.0 & 118.9 & 119.3 & 199.6 & 197.7 \\
$N=24$ & 27.5 & 95.3 & 95.8 & 118.9 & 119.4 & 197.4 & 194.8 \\
\hline
\end{tabular}


Table 2. Settlement ( $\mathrm{mm}$ ) for different material properties:

(a) Modular ratio

\begin{tabular}{cccccc}
\hline & $E_{c} / E_{s}$ & 15 & 30 & 45 & 60 \\
\hline$N=1$ & & 99.1 & 76.0 & 61.7 & 51.9 \\
& $s=1 \mathrm{~m}$ & 99.0 & 75.9 & 61.7 & 52.0 \\
$N=4$ & $s=2 \mathrm{~m}$ & 98.1 & 75.2 & 61.1 & 51.6 \\
& $s=3 \mathrm{~m}$ & 96.6 & 73.9 & 60.2 & 50.8 \\
& $s=4 \mathrm{~m}$ & 93.4 & 71.6 & 58.4 & 49.5 \\
\hline
\end{tabular}

Elastic case

(b) Column strength

\begin{tabular}{llrrcc}
\hline & $\phi_{c}$ & 35 & 40 & 45 & 50 \\
& $\psi_{c}$ & 5 & 10 & 15 & 20 \\
\hline$N=1$ & & 131.8 & 126.4 & 119.8 & 112.5 \\
& $S=1 \mathrm{~m}$ & 131.9 & 126.6 & 120.2 & 113.0 \\
$N=4$ & $s=2 \mathrm{~m}$ & 131.5 & 126.1 & 119.7 & 112.6 \\
& $S=3 \mathrm{~m}$ & 131.4 & 125.9 & 119.4 & 112.3 \\
& $s=4 \mathrm{~m}$ & 131.1 & 125.0 & 118.2 & 111.2 \\
\hline
\end{tabular}

Elasto-plastic case

(c) Soil strength

\begin{tabular}{llrrrr}
\hline & $\phi_{s}$ & 23 & 25 & 27 & 29 \\
& $c_{s}$ & 3 & 5 & 7 & 9 \\
\hline$N=1$ & & 199.1 & 158.1 & 139.1 & 130.8 \\
& $s=1 \mathrm{~m}$ & 196.8 & 158.6 & 139.9 & 131.6 \\
$N=4$ & $s=2 \mathrm{~m}$ & 197.2 & 158.1 & 138.6 & 130.2 \\
& $s=3 \mathrm{~m}$ & 200.5 & 160.2 & 139.2 & 130.0 \\
& $s=4 \mathrm{~m}$ & 204.4 & 163.5 & 141.5 & 130.8 \\
\hline
\end{tabular}

Plastic case 
Table 3. Settlement (mm) for different soil layer thicknesses.

\begin{tabular}{|c|c|c|c|c|c|c|}
\hline & $H$ & 2 & 4 & 6 & 8 & 10 \\
\hline No cc & umns & 81.0 & 166.9 & 236.3 & 262.6 & 277.6 \\
\hline 2D & & 44.7 & 115.2 & 171.6 & 197.2 & 206.6 \\
\hline Circu & & 42.7 & 109.8 & 161.8 & 188.0 & 198.5 \\
\hline$N=1$ & & 43.3 & 112.0 & 165.0 & 187.1 & 199.1 \\
\hline \multirow{4}{*}{$N=4$} & $s=1 \mathrm{~m}$ & 46.1 & 112.1 & 163.9 & 187.3 & 196.8 \\
\hline & $s=2 \mathrm{~m}$ & 50.7 & 117.3 & 167.3 & 187.0 & 197.2 \\
\hline & $s=3 \mathrm{~m}$ & 55.3 & 122.6 & 171.6 & 190.9 & 200.5 \\
\hline & $s=4 \mathrm{~m}$ & 59.3 & 127.3 & 175.2 & 196.2 & 204.4 \\
\hline
\end{tabular}

Plastic case 
Table 4. Settlement (mm) for different column lengths.

\begin{tabular}{lcccccc}
\hline$L$ & 2 & 4 & 5 & 6 & 8 & 10 \\
\hline 2D & 284.2 & 273.9 & 259.3 & 240.9 & 212.4 & 206.6 \\
2D* & 274.5 & 245.2 & 234.6 & 225.3 & 219.7 & 218.1 \\
Circular & 267.6 & 255.7 & 242.0 & 224.0 & 197.5 & 198.5 \\
$N=1$ & 268.7 & 254.6 & 240.4 & 222.4 & 198.2 & 199.1 \\
$N=4$ & 258.8 & 233.8 & 220.5 & 209.0 & 199.6 & 198.7 \\
$N=8$ & 254.5 & 225.6 & 213.9 & 203.9 & 199.4 & 198.4 \\
$N=12$ & 256.4 & 226.6 & 214.9 & 204.1 & 199.2 & 198.3 \\
$N=16$ & 253.6 & 224.3 & 212.4 & 203.6 & 199.1 & 198.1 \\
\hline
\end{tabular}

Plastic case, columns on the sides

2D: central column; 2D*: equivalent cylindrical trench 
Table 5. Settlement $(\mathrm{mm})$ for different area replacement ratios.

\begin{tabular}{|c|c|c|c|c|c|}
\hline & \multicolumn{2}{|c|}{$L=2 B$} & \multicolumn{2}{|c|}{$L=B$} \\
\hline & & $a_{r}=20 \%$ & $a_{r}=30 \%$ & $a_{r}=20 \%$ & $a_{r}=30 \%$ \\
\hline \multicolumn{2}{|l|}{$2 \mathrm{D}$} & 150.0 & 112.6 & 217.1 & 193.5 \\
\hline \multicolumn{2}{|c|}{ Circular } & 143.1 & 106.1 & 214.1 & 190.9 \\
\hline \multicolumn{2}{|c|}{$N=1$} & 144.3 & 106.9 & 212.1 & 187.9 \\
\hline \multirow{2}{*}{$N=4$} & $s=2 \mathrm{~m}$ & 146.1 & 109.6 & 191.2 & 169.7 \\
\hline & $s=3 \mathrm{~m}$ & 151.3 & 116.4 & 182.8 & 155.6 \\
\hline
\end{tabular}




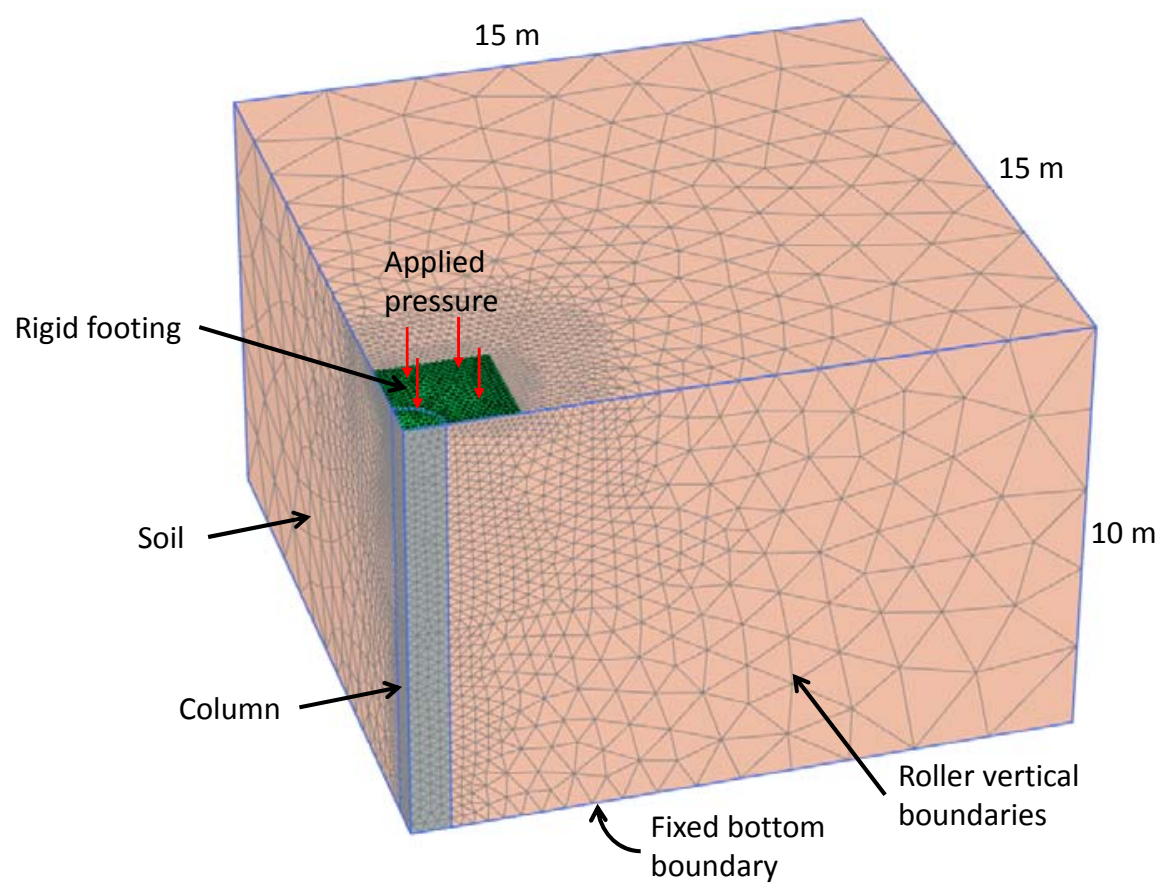

Figure 1. 3D finite element model. Reference case. 


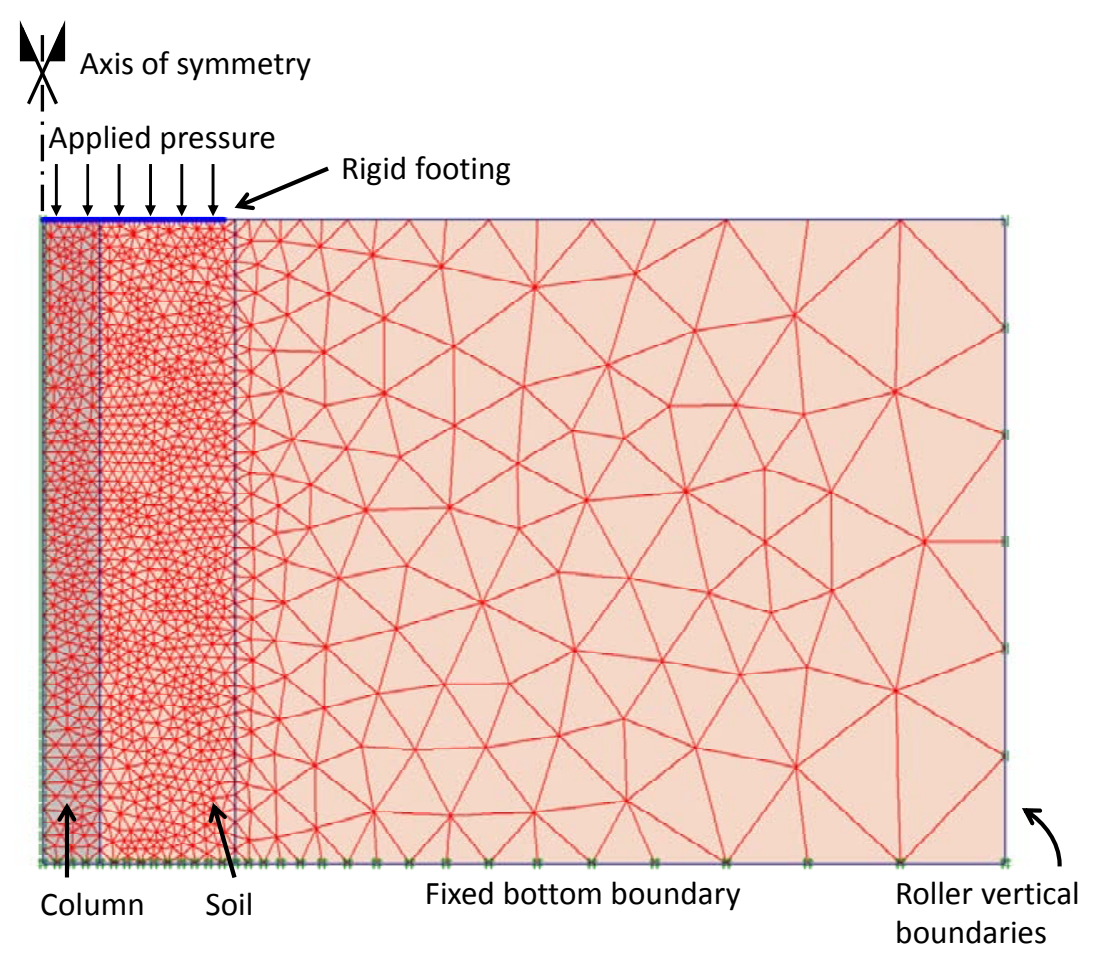

Figure 2. 2D finite element model. Reference case. Circular footing. 


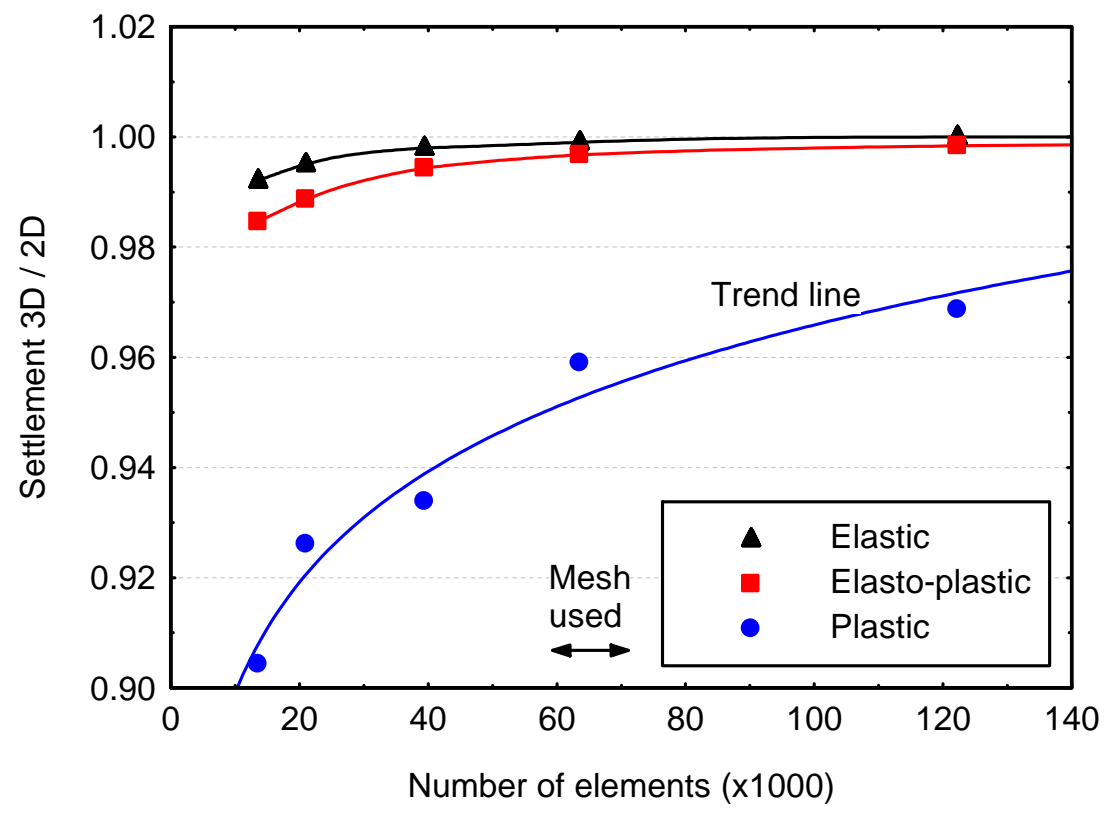

Figure 3. Mesh sensitivity analyses. 

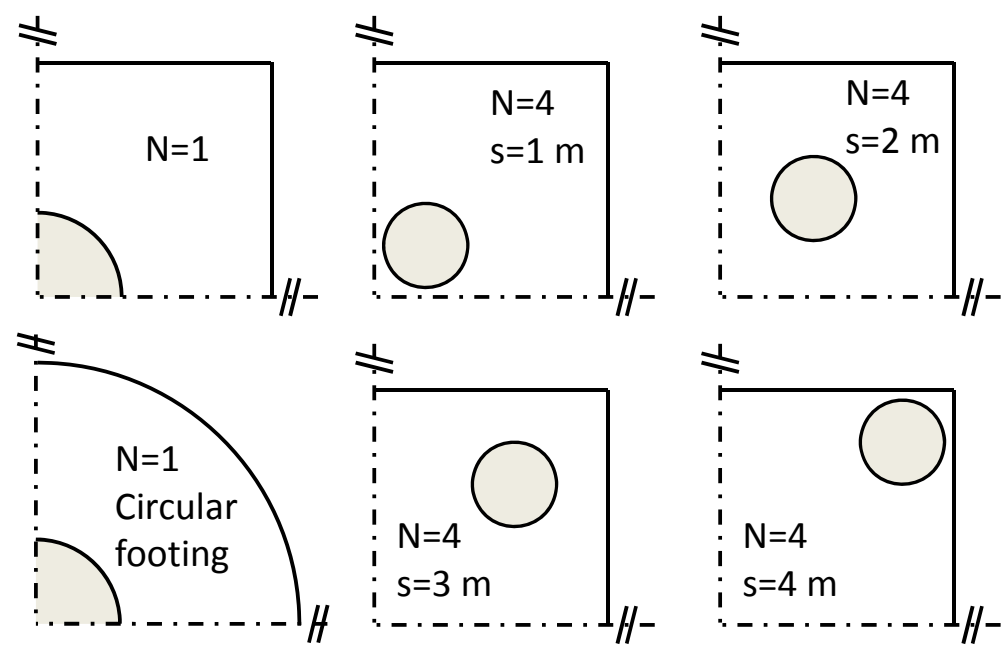

Figure 4. Groups of stone columns for different spacings. 


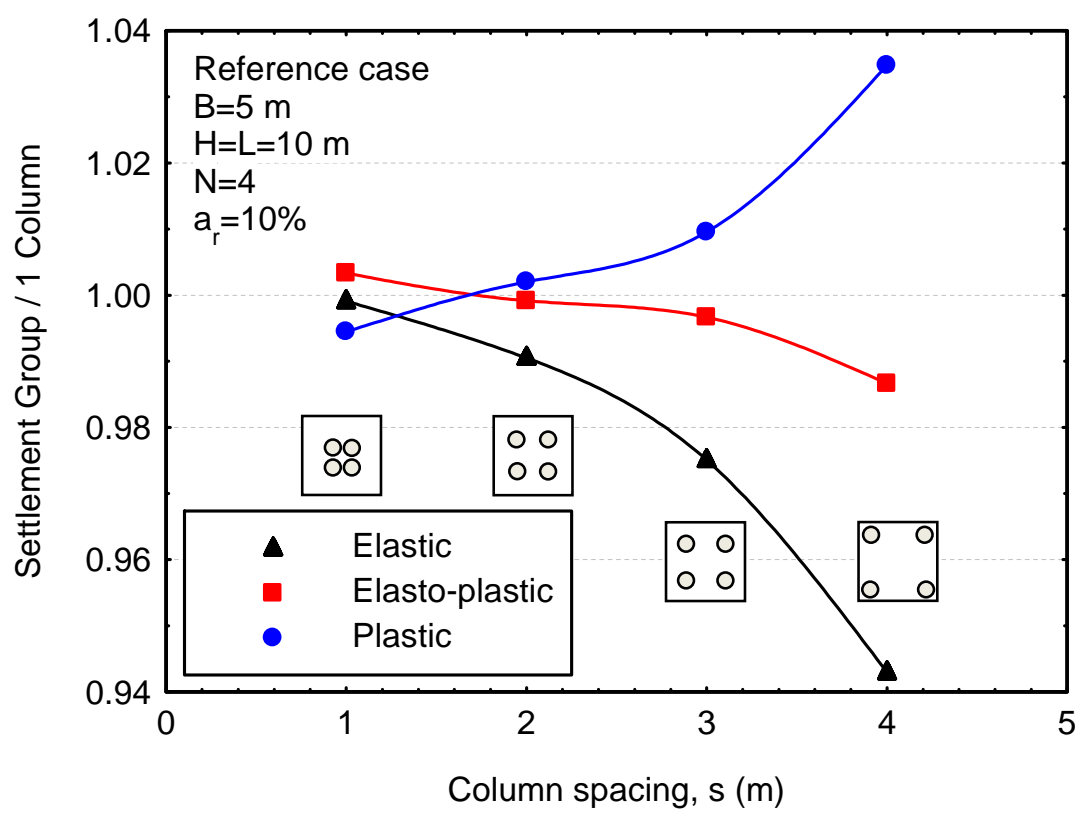

Figure 5. Influence of column position. 


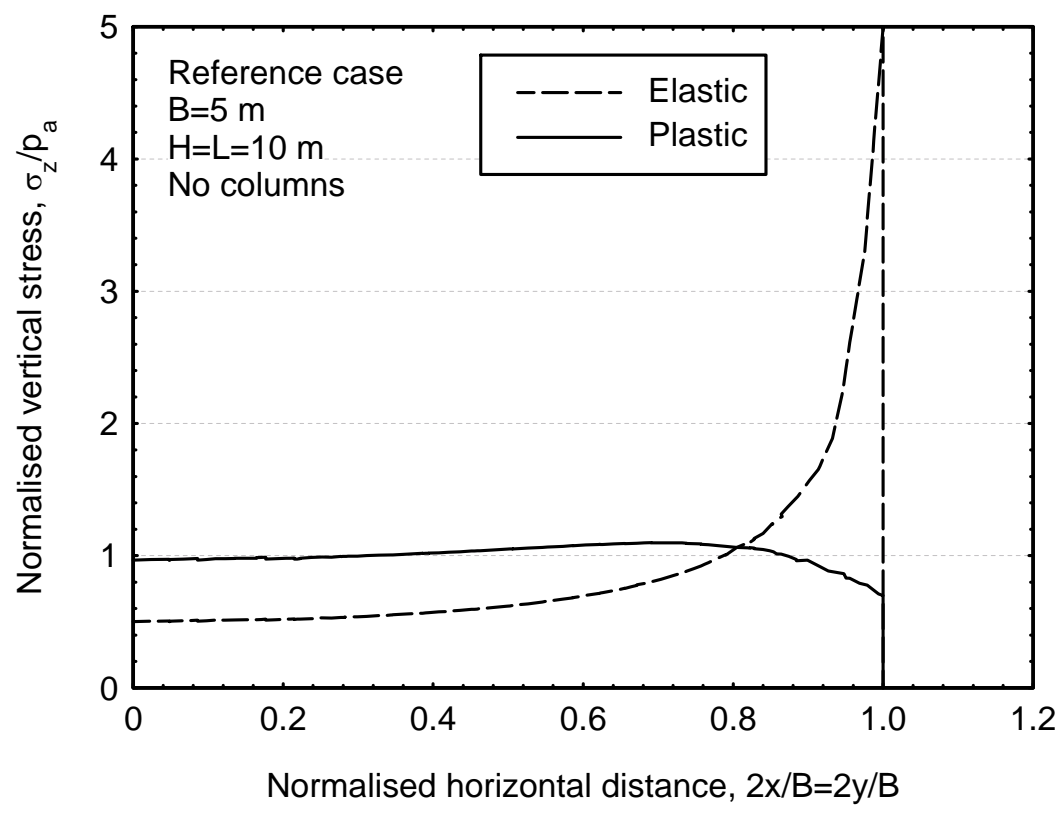

(a) No columns

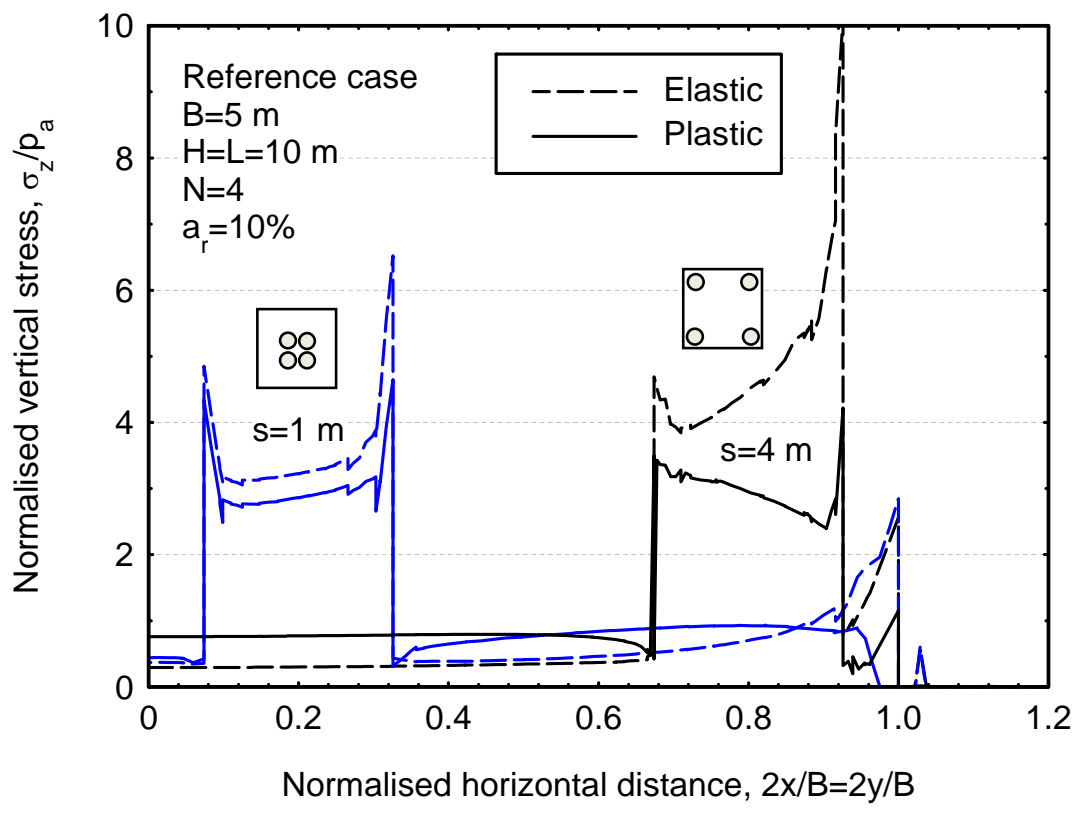

(b) $N=4$

Figure 6. Vertical stresses beneath the footing. Diagonal section. 


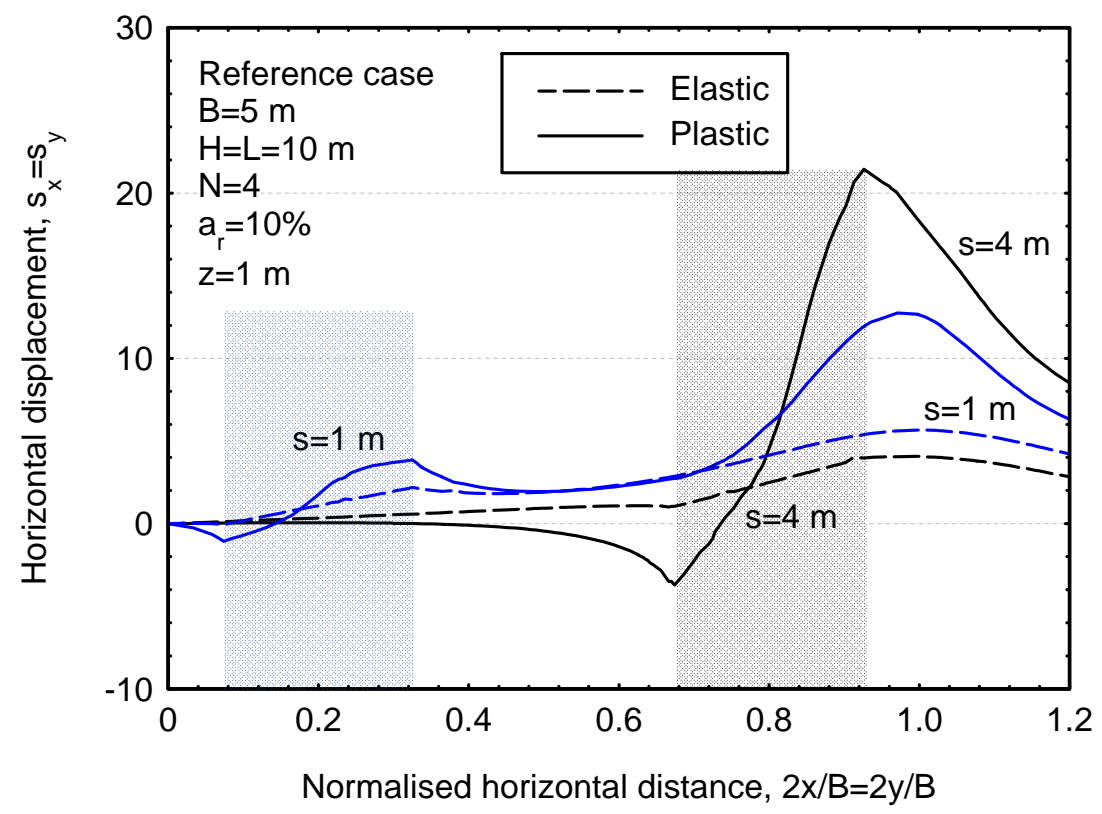

Figure 7. Horizontal displacements at $1 \mathrm{~m}$ depth. Diagonal section. 


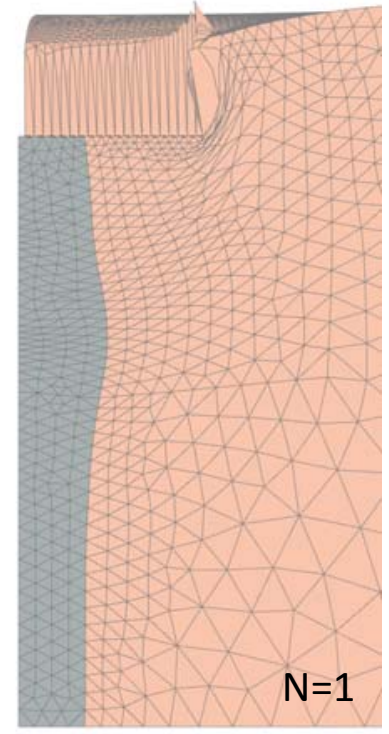

(a)

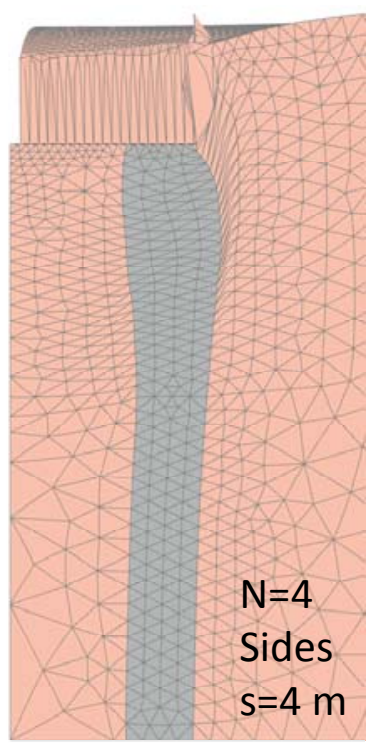

(b)

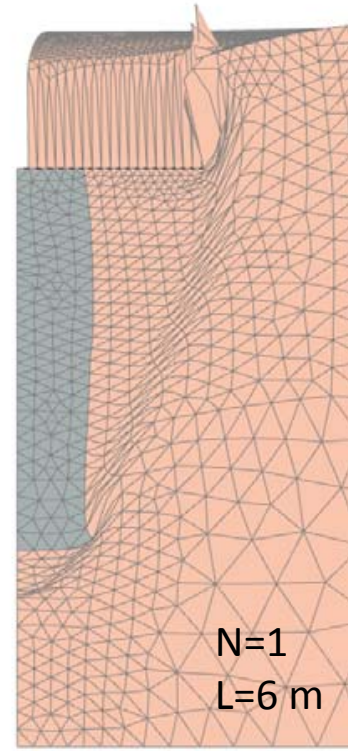

(c)

Figure 8. Deformation modes: (a) Bulging; (b) Shearing; (c) Punching. Deformed mesh (amplified 10 times). Cross section. 

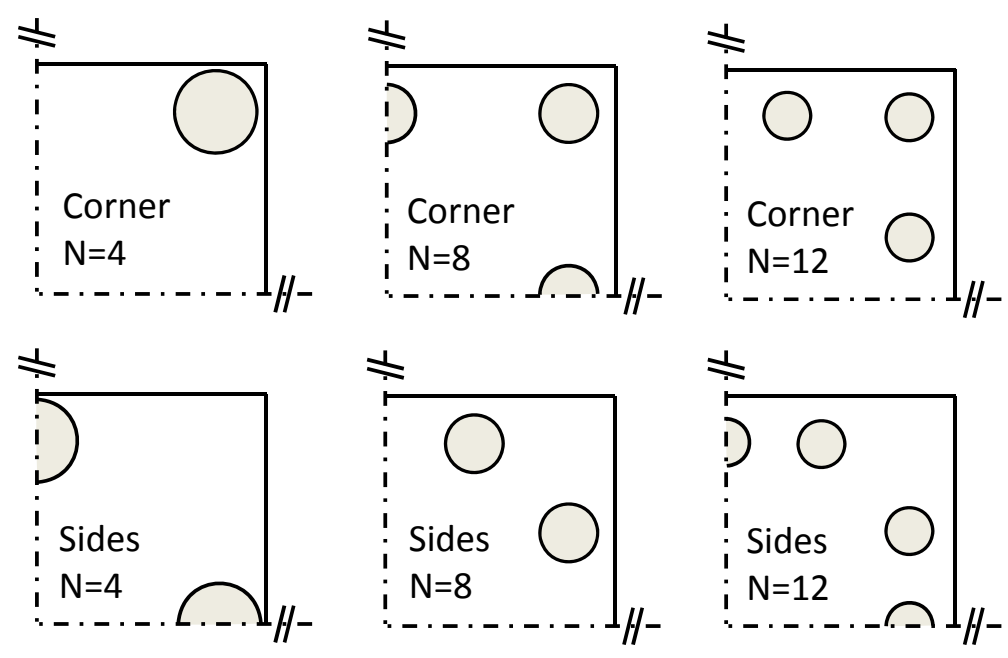

Figure 9. Groups of stone columns for different number of columns. 


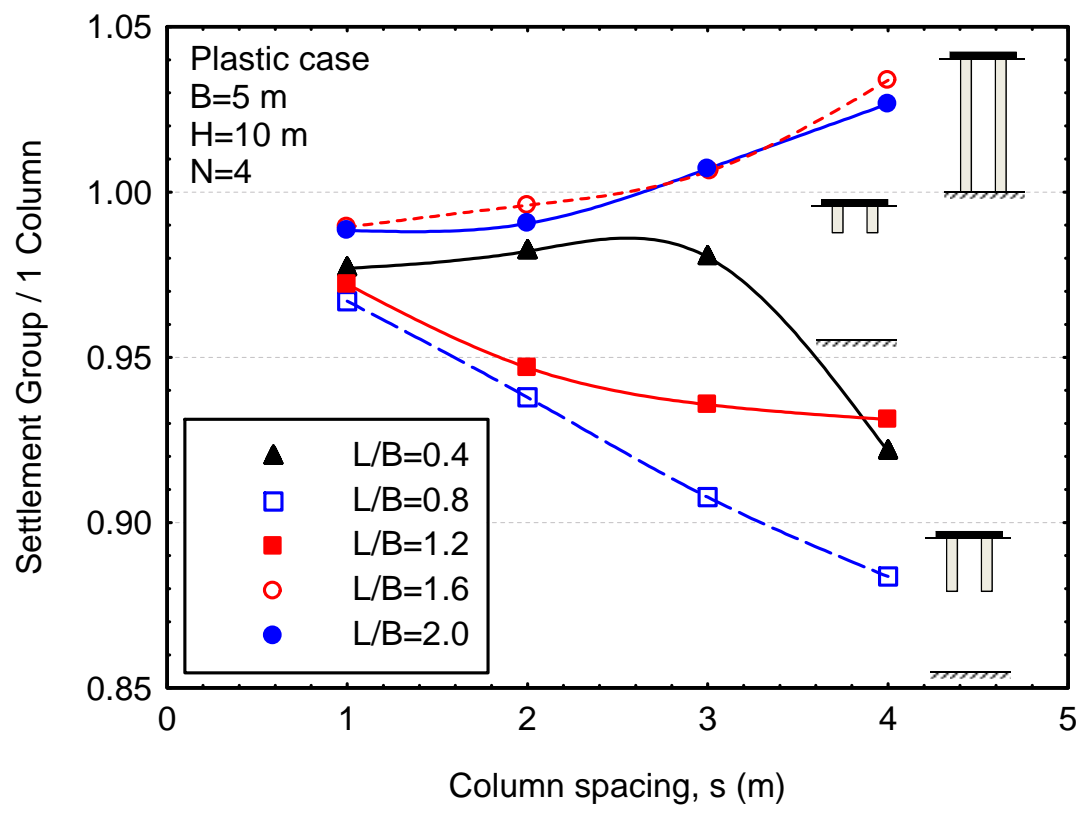

Figure 10. Influence of column length for different column positions. 


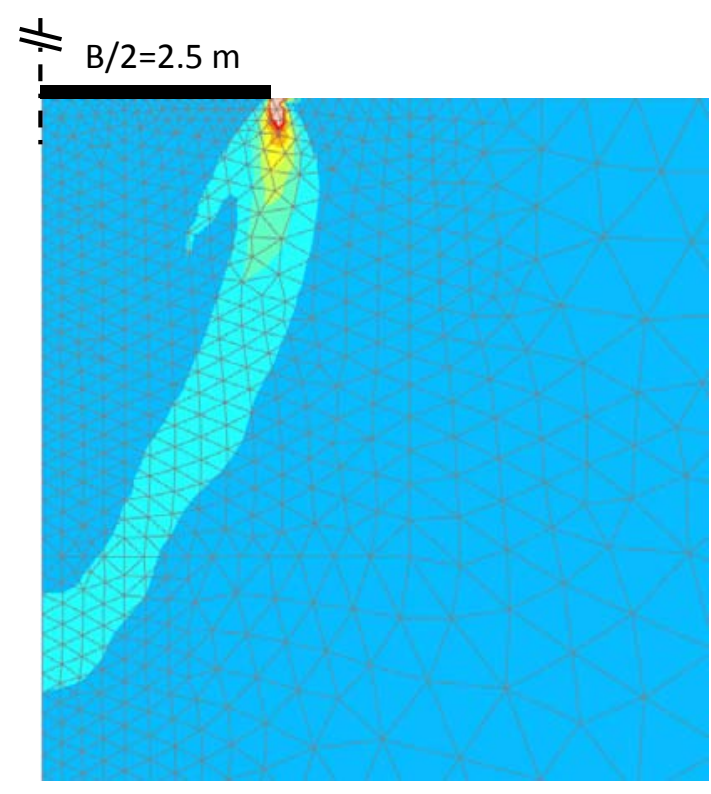

(a)

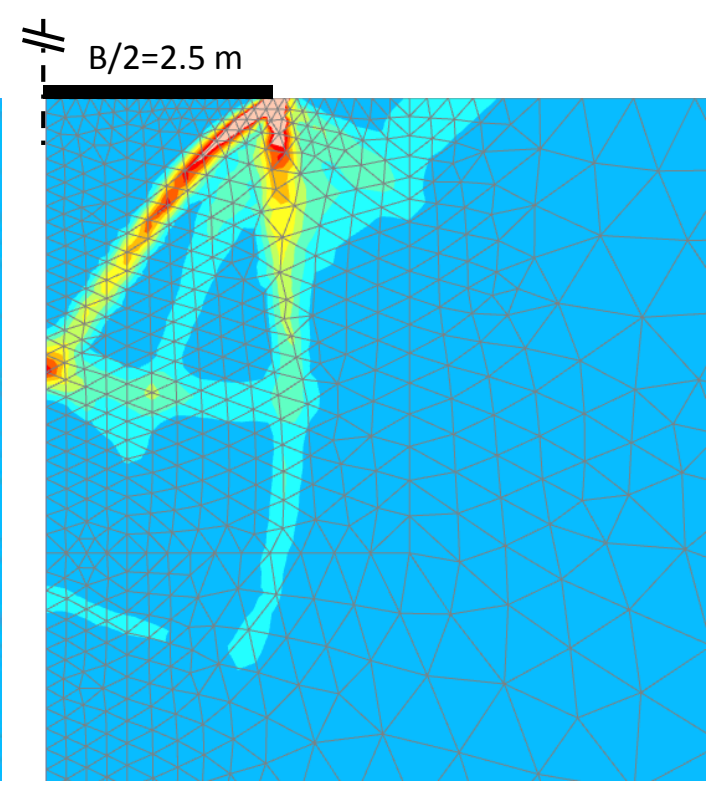

(b)

Figure 11. Incremental shear strains beneath the rough rigid footing. No columns. Cross section. (a)

$$
p_{\text {app }}=100 \mathrm{kPa} \text {; (b) } p_{\text {app }} \approx 180 \mathrm{kPa} \text {, at failure. }
$$




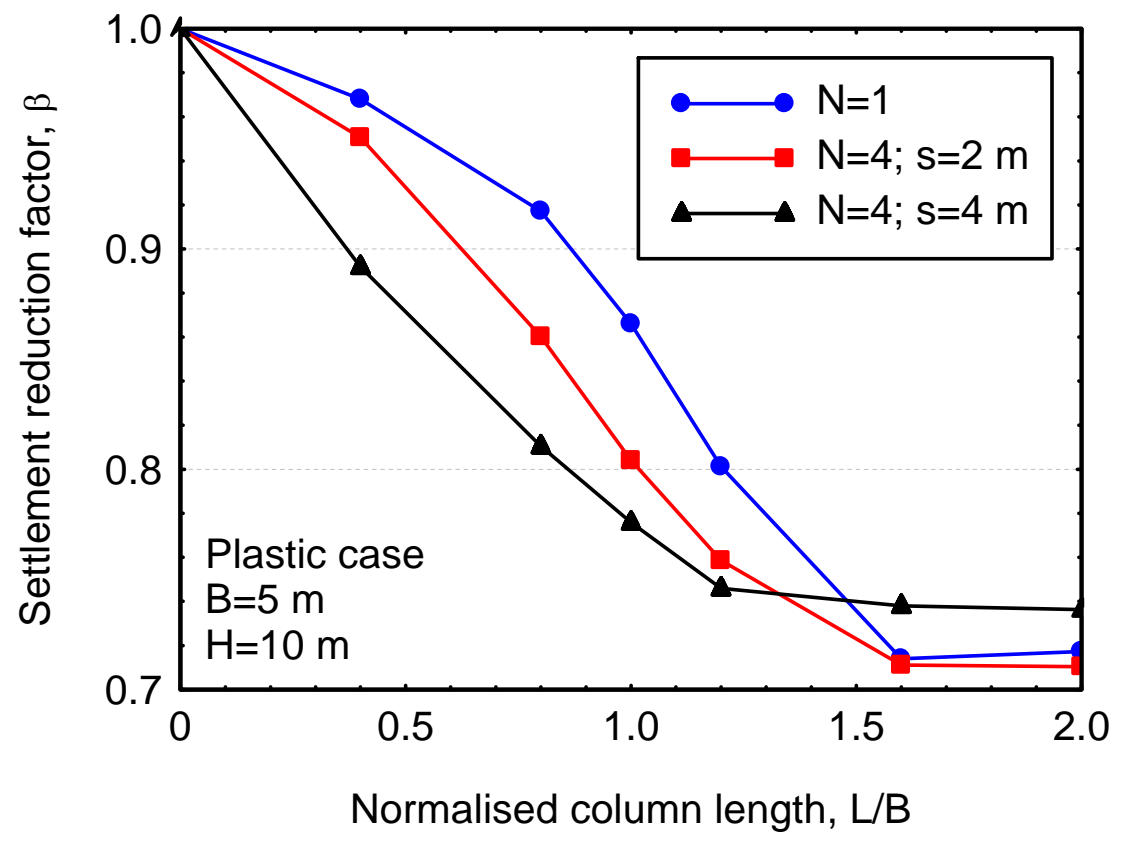

Figure 12. Settlement reduction for different column lengths. 


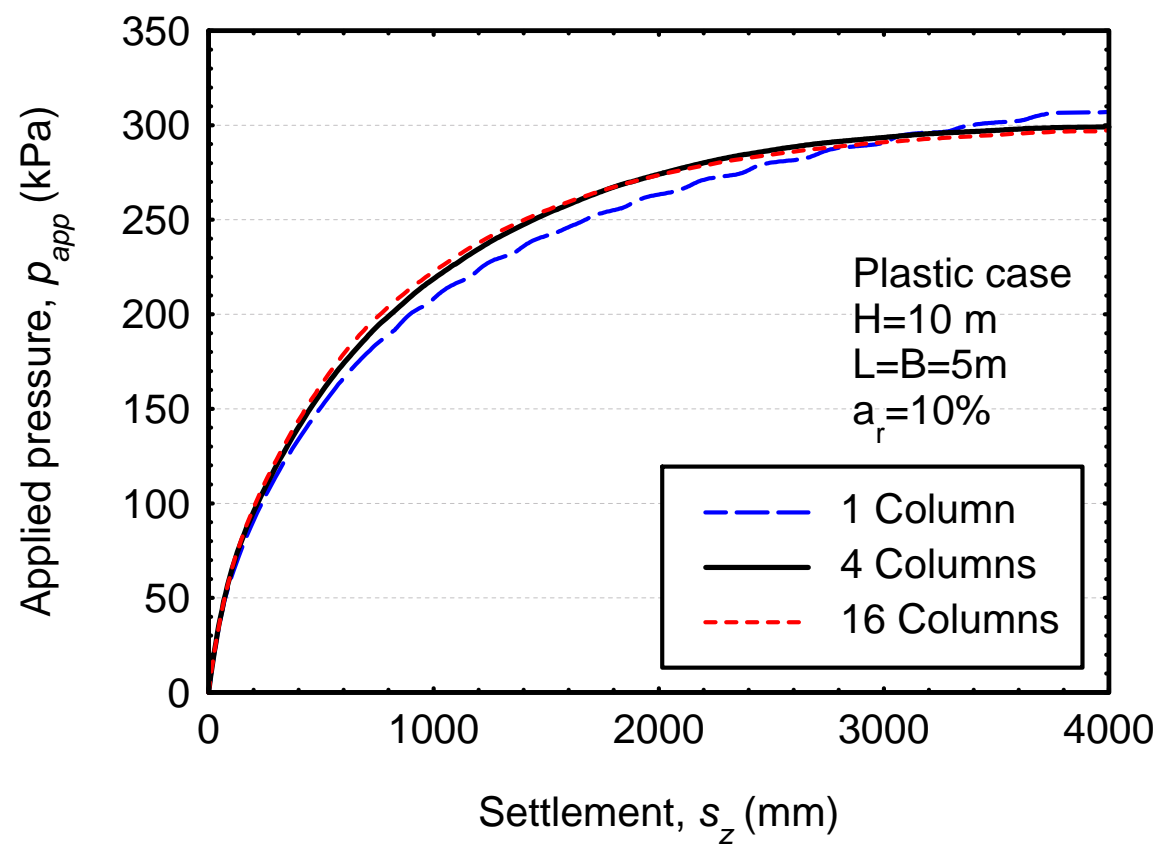

Figure 13. Load-settlement curves. 

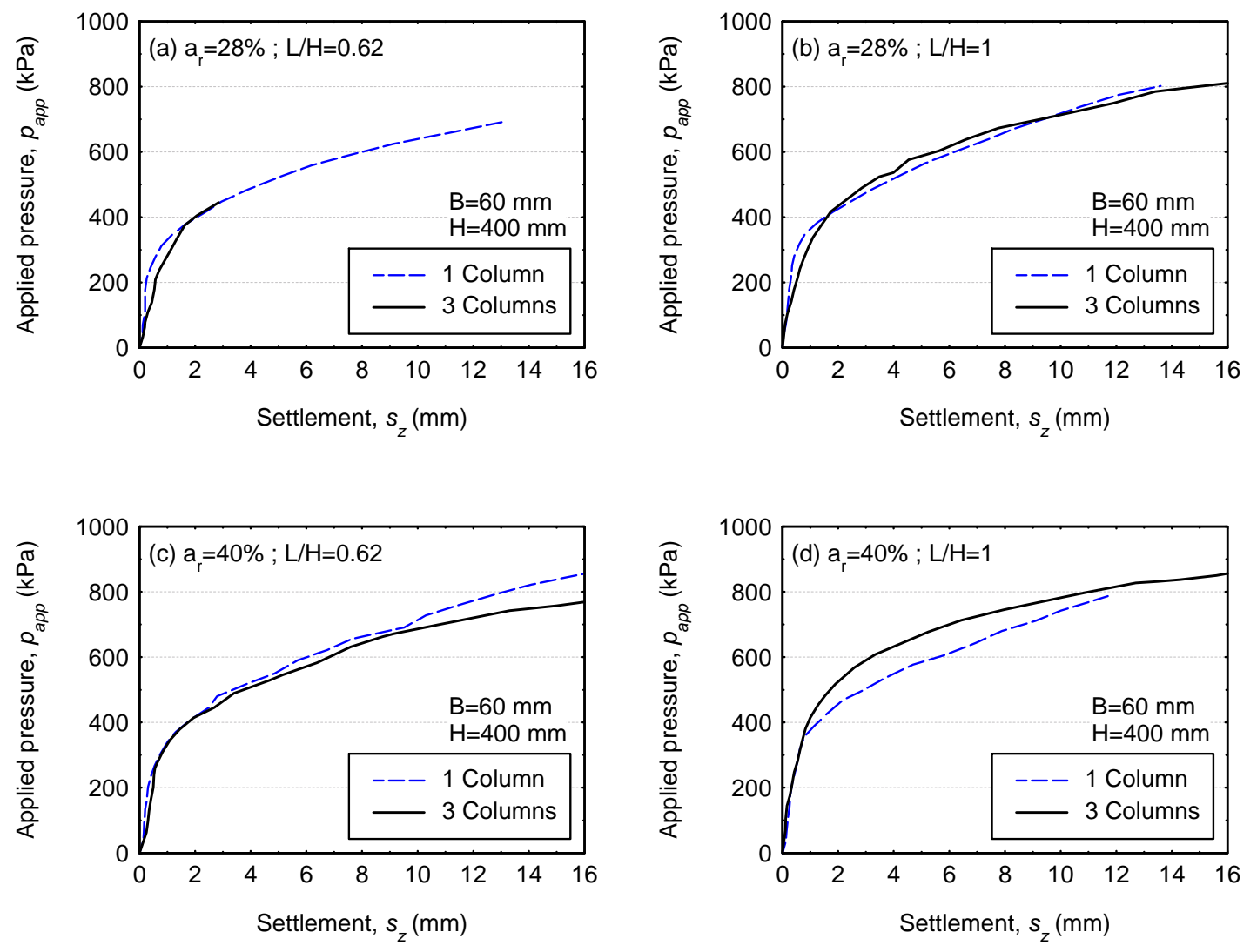

Figure 14. Comparison between small-group and isolated column. Laboratory tests (Data taken from Black et al. [9]). 

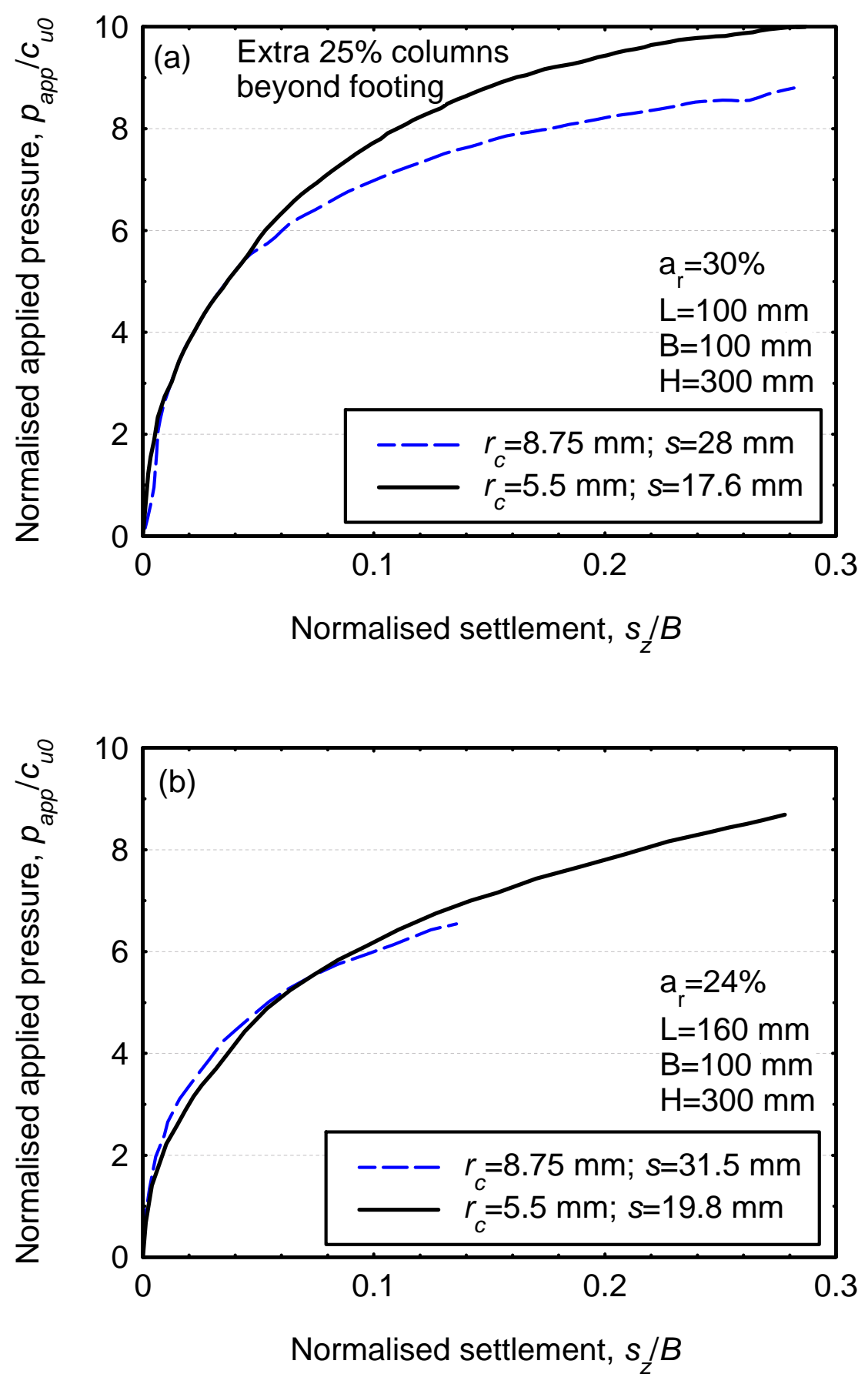

Figure 15. Comparison between different number of columns. Laboratory tests (Data taken from Wood et al. [6]). 


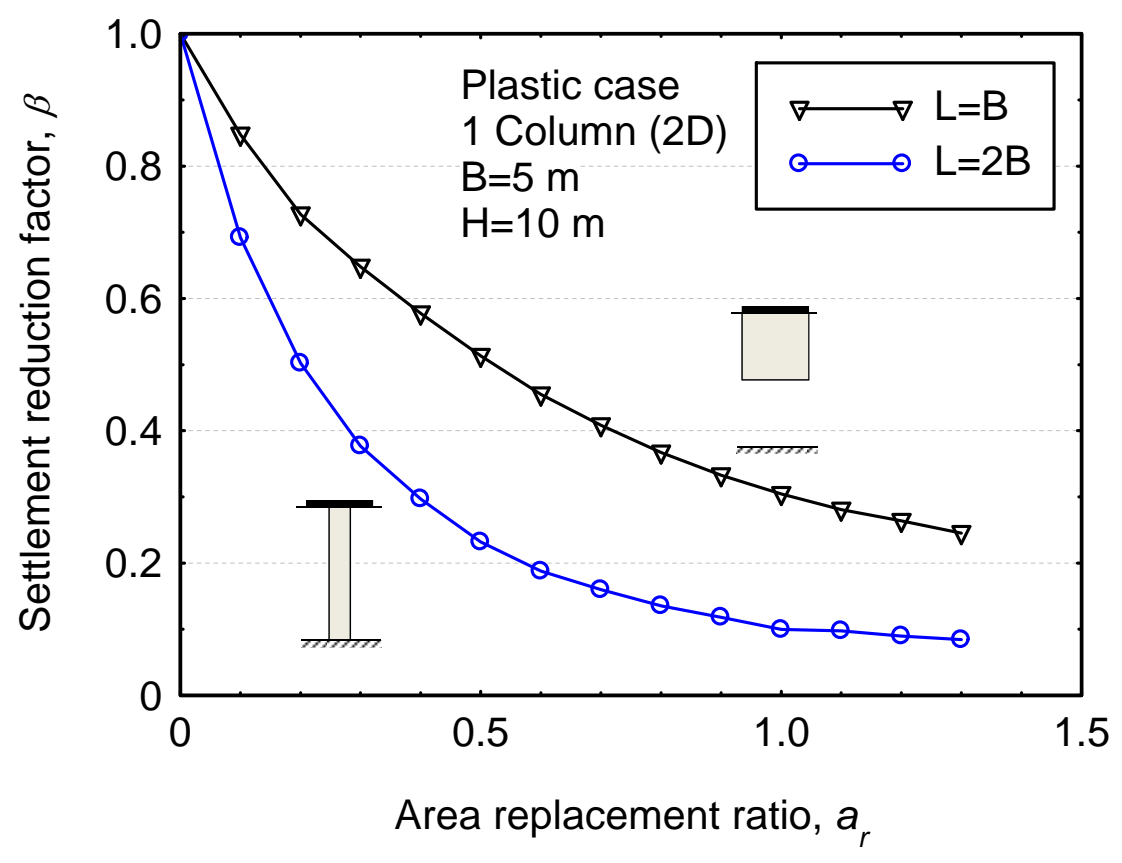

(a) Settlement reduction

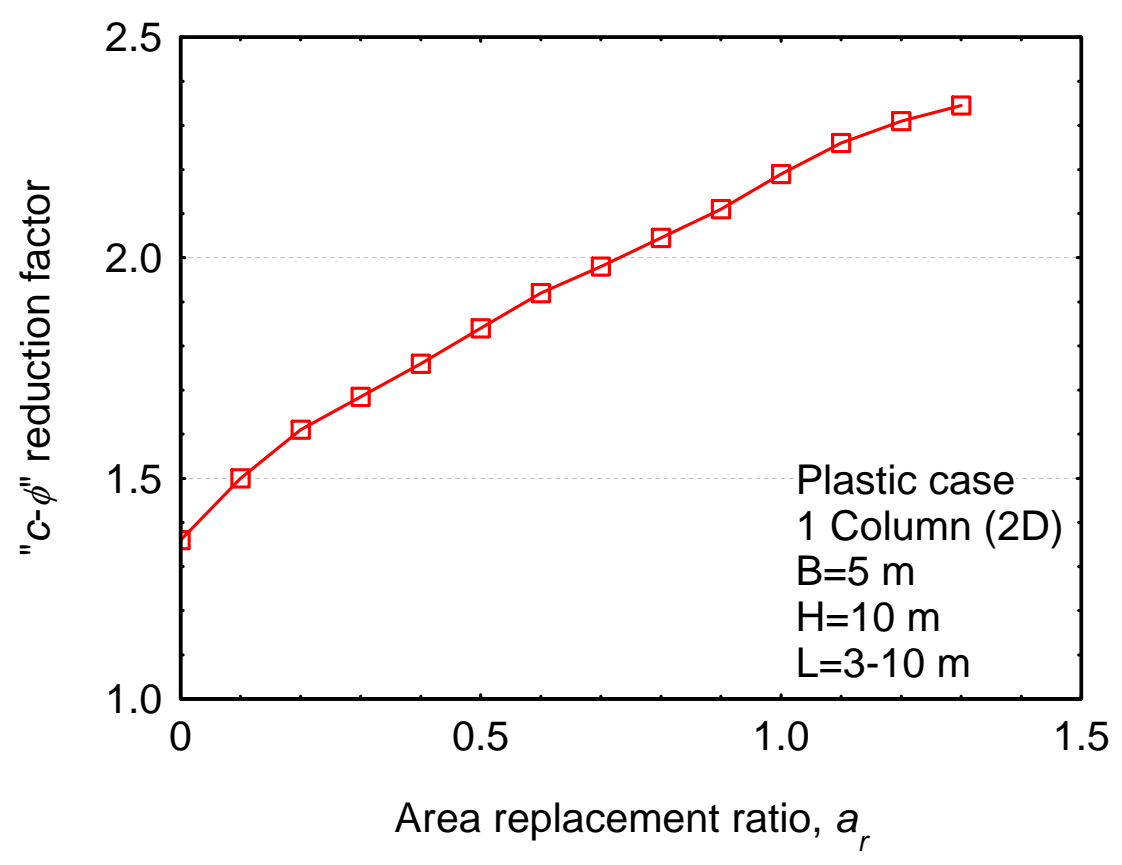

(b) Bearing pressure

Figure 16. Effectiveness of area replacement ratio in group of columns. 


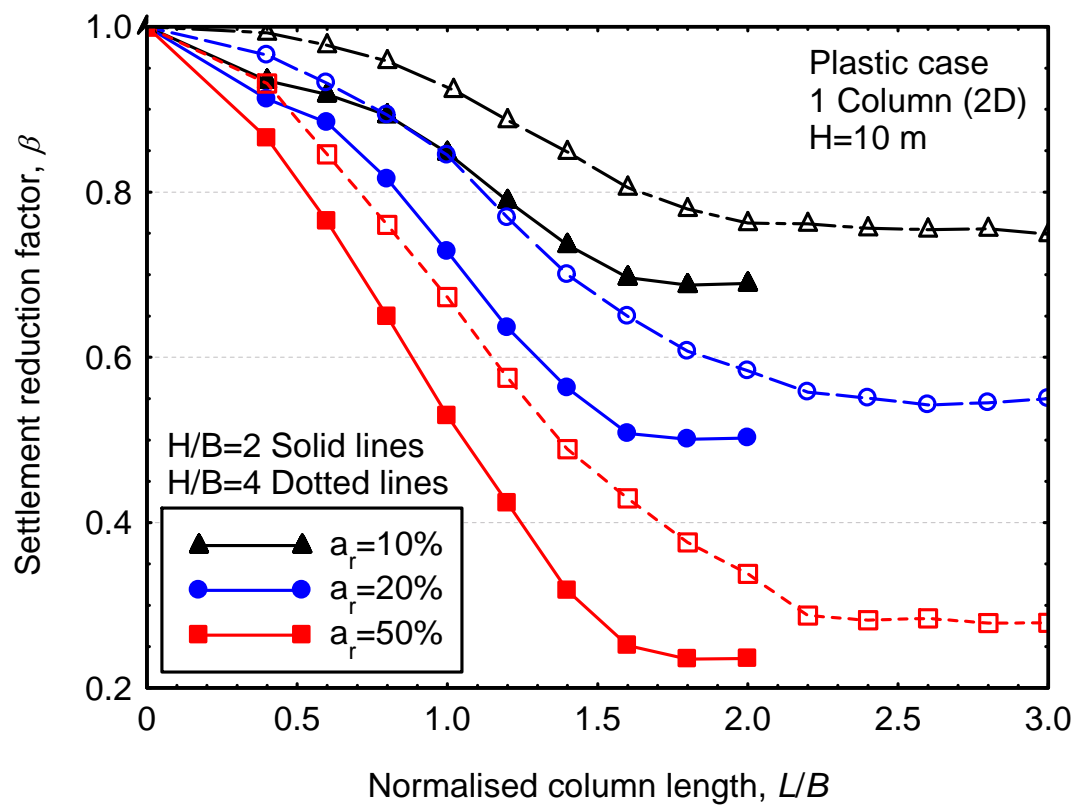

Figure 17. Critical column length for different area replacement ratios. 